MATEC Web of Conferences 39, 01008 (2016)

DOI: $10.1051 /$ matecconf/20163901008

C) Owned by the authors, published by EDP Sciences, 2016

\title{
MECHANICAL AND MORPHOLOGICAL PROPERTIES OF NANO FILLER POLYESTER COMPOSITES
}

\author{
Noor Najmi Bonnia ${ }^{1, a}$, Aein Afina Redzuan ${ }^{2}$ and Nurul Shakirah Shuhaimeen ${ }^{2}$ \\ ${ }^{1}$ Nanocomposite Material \& industrial Applications Research Group ,Faculty of Applied Sciences, Universiti Teknologi Mara Shah Alam \\ 40450 Selangor, Malaysia \\ ${ }^{2}$ Materials Technology Programme, Faculty of Applied Sciences, Universiti Teknologi Mara Shah Alam 40450 Selangor, Malaysia
}

\begin{abstract}
This research is focusing on mechanical and morphological properties of unsaturated polyester (UP) reinforced with two different types of filler which is nano size clay Cloisite 30B (C30B) and Carbon Black (CB). Samples were fabricated via hand lay-up and open molding technique. Percentages of Cloisite 30B \& Carbon Black (CB) used vary from $0,2,4,6,8$ and $10 \mathrm{wt} \%$. The mechanical properties were evaluated by impact, flexural and hardness testing. Result shows that the mechanical strength of $\mathrm{C} 30 \mathrm{~B}$ was better compare to $\mathrm{CB}$ filled composite. The combination of UP with $\mathrm{C} 30 \mathrm{~B}$ helps to improve the properties due to the high surface area of nanosize filler in the matrix. The result shows that increasing of filler content had increased mechanical properties of composites. Optimum percentage represent good mechanical properties are $4 \%$ for both fillers. SEM images showed that rough surface image indicate to agglomeration of filler in the matrix for CB sample and smooth surface image on C30B sample indicate to homogenous blending between filler and matrix polyester. SEM images proved that mechanical properties result indicate that $\mathrm{C} 30 \mathrm{~B}$ polyester composite is a good reinforcement compare to $\mathrm{CB}$ polyester composite.
\end{abstract}

\section{Introduction}

Polymer nanocomposites, especially polymer-layered silicate nanocomposite, represent a rational alternative to conventionally filled polymers. Because of their nanometer scale dispersion, it exhibit markedly improved properties such as lighter weight, outstanding barrier and good mechanical properties when compared with the pure polymers or conventional composites [1].

The addition of clays minerals (hydrophilic by nature) to polymers (mostly hydrophobic) can improve their mechanical performances, fire retardant and barrier resistance, and thermal and electrical conductivities, whereas optical properties are preserving when the mineral particles are sufficiently small. Clay mineral particles are generally required to perfectly disaggregate within the organic matrix, but their dispersion is affected by many factors [2].

Clay-polymer composites can be classified into three types: conventional composite, intercalated nanocomposites and exfoliated nanocomposites. In an exfoliated nanocomposite usually show greater phase homogeneity than intercalated nanocomposites because each nanolayer contributes fully to interfacial interactions with the matrix. Hence, exfoliated state is especially effective in improving the reinforcement and other performance properties of clay composite materials. Polymer layered nanocomposites can be classified into three types; (i) intercalated (ii) flocculated (iii) exfoliated nanocomposites [1]. These three conditions will contribute to different properties of composites produced.

The use of reinforcing fillers such as carbon black and nanosize clay gives the material unique properties, a combination of high conductivity with high strength. The small size of fillers leads to a dramatic increase in interfacial area. This interfacial area creates a significant volume fraction of interfacial polymer with properties different from the bulk polymer even at low loadings [3]. All of these phenomena were found on polymer nanocomposites upon dimension range from $1-1000 \mathrm{~nm}$ [4]. Matrix plays a major role to bonding with filler in composites. Unsaturated polyester (UP) commonly used in particle reinforced due to highly crosslink, low molecular weight and much brittle. The matrix materials popularly used in natural fibre composites range is from thermoplastics such as polypropylene and polyethylene, to thermosets such as polyester.

Unsaturated polyester (UP) can be dissolved in a polymerizable monomer such as styrene monomer. A UP is a long chain linear polymer containing a number a reactive double bonds. The styrene monomer, which also contains $\mathrm{C}$ and $\mathrm{C}$ reactive double bonds, acts as a curing agent by bridging adjacent polyester molecules at their unsaturation points. During the styrene- unsaturated polyester cross linking copolymerization, the initiator decomposes and creates free radicals in the system. The free radicals grow and form long-chain molecules by

\footnotetext{
a Corresponding author: noornajmi@salam.uitm.edu.my
} 
connecting styrene monomers and unsaturated polyester molecules by both inter- and intramolecular reactions.

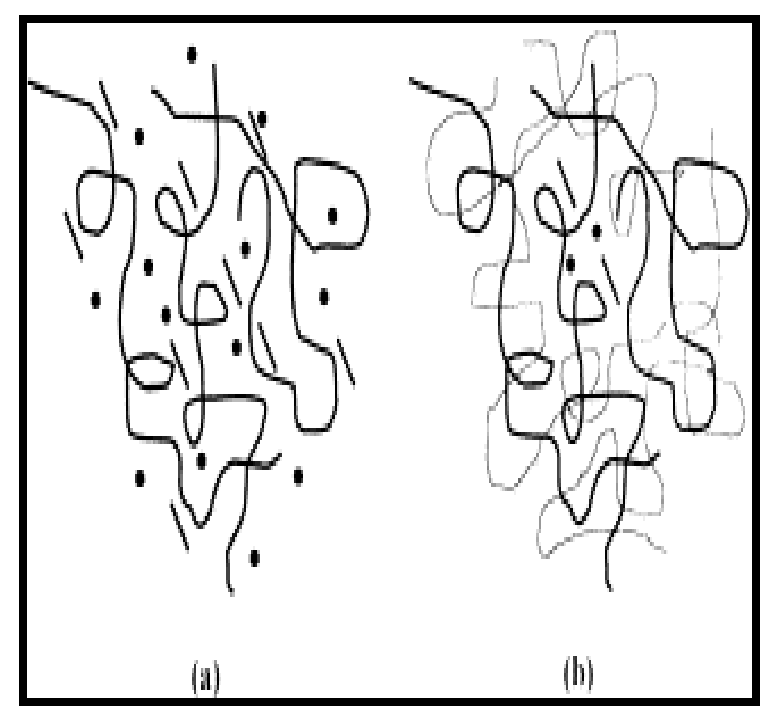

Figure 1: Curing mechanism of UP: (a) styrene-UP solution mixture before curing; and (b) after curing. (dot, styrene monomer; bold line, uncured unsaturated polyester chain; line, polymerized-styrene chain connecting the unsaturated points of unsaturated polyester).

Polyester resins are widely used as a matrix in polymer composites, but polymerization of this resin will result in brittleness due to high cross linking level. Unsaturated polyester enables to modify performance with low additive profiles [5]. The ideal fraction of filler loading (1-5 wt \%) resulting on composite property improvement compared to $(10-20$ wt \%) [6]. The selection properties of filler are important to enhance strength and cost reduction obviously. Cloisite $30 \mathrm{~B}$ and Carbon Black have good properties in composite materials. Carbon black is already widely known to be use as reinforcement in not just vulcanized rubber products especially in tires applications, but also as pigments for plastics, coating, ink, and inkjet applications and enhancing the mechanical properties of the carbon filled composites. Cloisite ${ }^{\circledR} 30 \mathrm{~B}$ is an additive and natural montmorillonite for plastics to improve various plastic physical properties, such as reinforcement, HDT, CLTE and barrier.

This study was undertaken to investigate the mechanical and morphological properties of polyester nanocomposite with different types of nanosize filler.

\section{Experimental}

\subsection{Raw Materials}

Unsaturated polyester Reversol UN 8100 P-8542CSH from Revertex Sdn. Bhd. Malaysia was used in this research. Crosslink was initiated by adding $1 \%$ of cobalt octanoate and methyl ethyl ketone peroxide (MEKP) catalyst to the resin-clay mixture at room temperature as recommended by the manufacturer [7]. Natural montmorillonite Cloisite ${ }^{\circledR} \quad 30 \mathrm{~B} \quad(\mathrm{C} 30 \mathrm{~B})$, a natural montmorillonite modified with methyl tallow bis-2hydroxyethyl quarternary ammonium salt (chloride) supplied from Southern Clay Products. Carbon black (CB) was supplied by Quandin, China.

\subsection{Preparation of composite}

To eliminate moisture, carbon black \& cloiste 30 B was first dried in the oven for $24 \mathrm{~h}$ and cooled to room temperature. Different compositions of fillers were used in producing the composite $(0,2,4,6,8$, and $10 \mathrm{wt} \%$ filler). Filler was added and stirred for 4 hours in preparing the polyester/carbon black \& polyester/Cloisite 30B composite. The cured sample boards were cut to the required ASTM standards for each test. The mixing were cast into mold and leave for 24 hours at room temperature followed by post curing at elevated temperature [8].

\section{Characterization and Testing}

Impact testing was carried out with a Ray Ran Pendulum Impact System according ASTM D 256 standard. The flexural properties were determined under three-point bending using an Instron 5569 Universal Testing Machine (UTM) according to ASTM standard. All samples were placed at room temperature. Hardness test was measured using Shore-D. The morphology of polymer nanocomposites was observed using FESEM; ZEISS Supra $40 \mathrm{VP}$.

\section{Result and discussion}

\subsection{Impact strength}

Impact test is a method for determining behavior of materials when subjected to shock loading in bending, tension or torsion. Fig. 2 shows impact properties of polyester $\mathrm{C} 30 \mathrm{~B}$ composites and polyester $\mathrm{CB}$ composites. Increasing percentage of filler had improved the impact strength of polyester resin. Highest impact strength was observed at $4 \%$ wt of Cloisite $30 \mathrm{~B}$ filler which is 2.86 $\mathrm{kJ} / \mathrm{m}^{2}$. Addition more than $4 \% \mathrm{wt}$ of filler decreased the impact strength.

C30B polyester composite give higher impact strength compare to $\mathrm{CB}$ composite. This is due to the organically treated clay with methyl tallow bis 2-hydroxyethyl ammonium chloride. The modified clay with lower surface energy and polymer with different polarities was entered the space between the layers and cause further separation of the silicate layers to form the nanocomposites. The filler dispersion occurs an either exfoliated or intercalated nanocomposites was achieved. Compared to $\mathrm{CB}$, it shown less surface contact and unable in reduce degree of crosslinking content. The presence of $\mathrm{CB}$ as a filler much related to increase the electrical conductivity properties of materials [9]. 


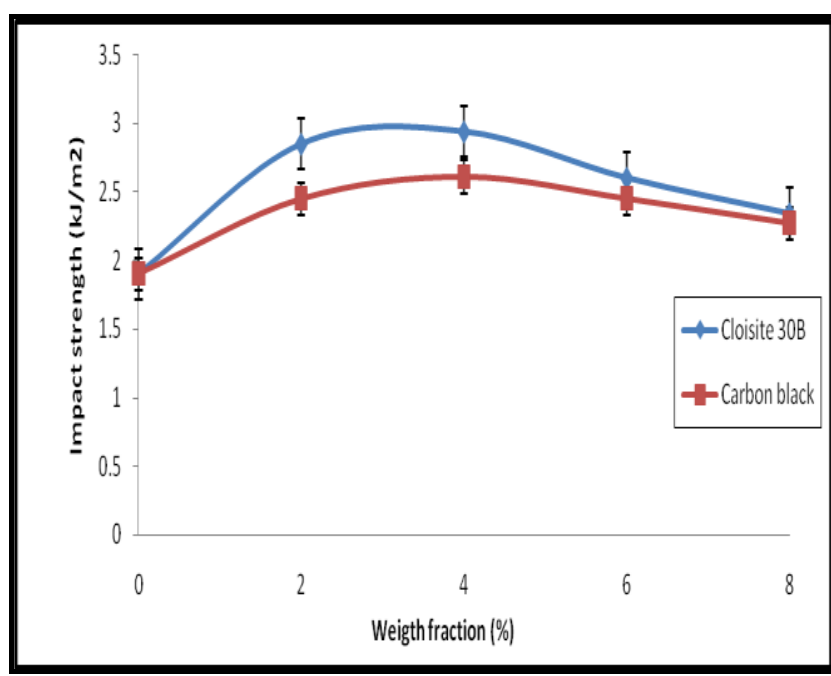

Figure 2: Impact strength of nanocomposites

\subsection{Hardness}

The graph showed in Fig 3 that a hardness value of UP sample was 68.0. Both containing $2 \mathrm{wt} \% \mathrm{C} 30 \mathrm{~B}$ and $\mathrm{CB}$ was spotting the difference on hardness increased to 75.5 and 74.2 respectively. The percentage of improvement for both $\mathrm{C} 30 \mathrm{~B}$ and $\mathrm{CB}$ particle in $4 \mathrm{wt} \%$ compare than unfilled UP are $14.7 \%$ and $12.3 \%$ respectively. With increased the weight fraction of $\mathrm{C} 30 \mathrm{~B}$ from $2 \mathrm{wt} \%$ until $4 \mathrm{wt} \%$, it increased rapidly from 75.5 to 78.0 , and then further decreased to 73.4 as contains of $8 \mathrm{wt} \%$.

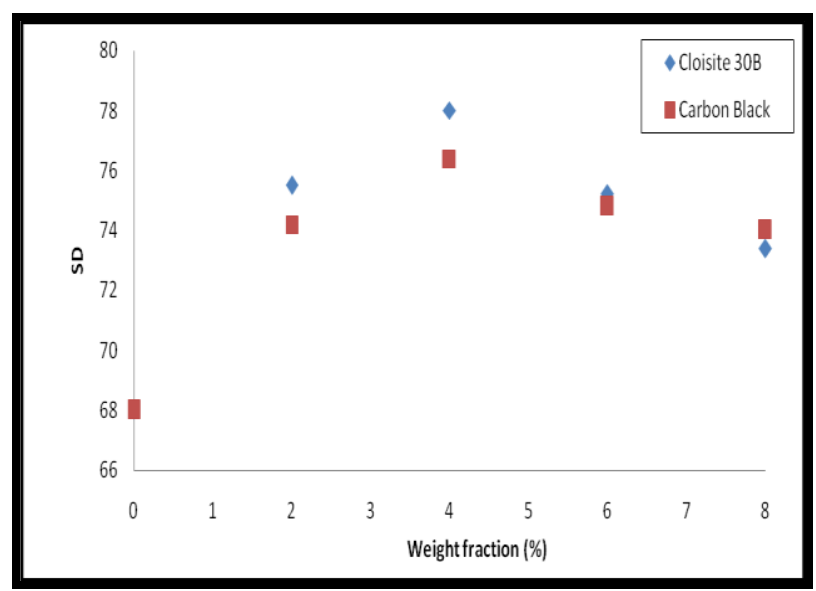

Figure 3: Effect of $\mathrm{C} 30 \mathrm{~B}$ and $\mathrm{CB}$ percentage in UP was changed hardness property

Shore D hardness is a measurement of the resistance of hardened steel rod $1.1 \mathrm{~mm}-1.4 \mathrm{~mm}$ diameter, with a $30^{\circ}$ conical point, $0.1 \mathrm{~mm}$ radius tip material. This method represents the higher of number, the greatest of resistance. Addition of filler had increased value of hardness. Obviously $\mathrm{C} 30 \mathrm{~B}$ much tends to enhance the non-deformability of the composite. Quanlin et al. [10] stated, hardness increased with increasing of filler content, compared with unfilled UPR resin. Consequently, the composite is highly probability to become easily deformation by caused the increasing number of pores between filler and matrix.

\subsection{Flexural Properties}

The flexural strength and flexural modulus of the composites showed in Fig 4. The reinforcement of Cloisite 30B (C30B) and Carbon Black (CB) causes a considerable change in the flexural properties. Flexural strength increased with increasing of the filler loading. The flexural strength of $\mathrm{C} 30 \mathrm{~B} / \mathrm{UP}$ and $\mathrm{CB} / \mathrm{UP}$ in $4 \mathrm{wt} \%$ was $90.85 \mathrm{MPa}$ and $76.59 \mathrm{MPa}$. After $4 \%$ of filler loading, result shows the decrement of flexural strength for both composites. This is due to a lower degree of exfoliation and a lower degree of polymer-Cloisite 30B surface interactions at higher filler content [11]. Cloisite 30B (C30B) give higher flexural strength compare to Carbon Black (CB) due to compatibility between C30B and polyester matrix help to improve the interaction with the matrix.

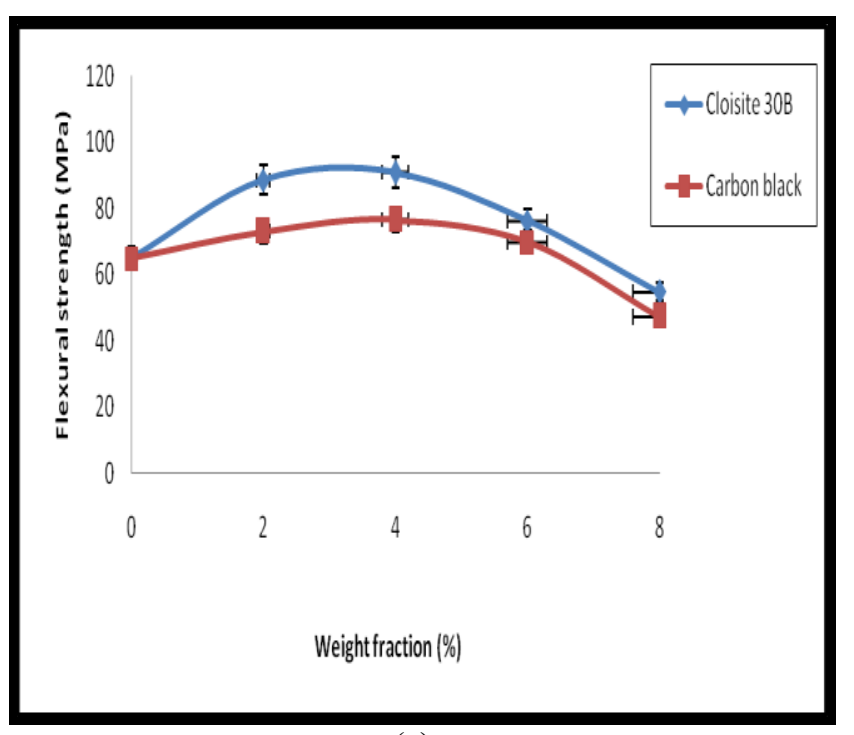

(a)

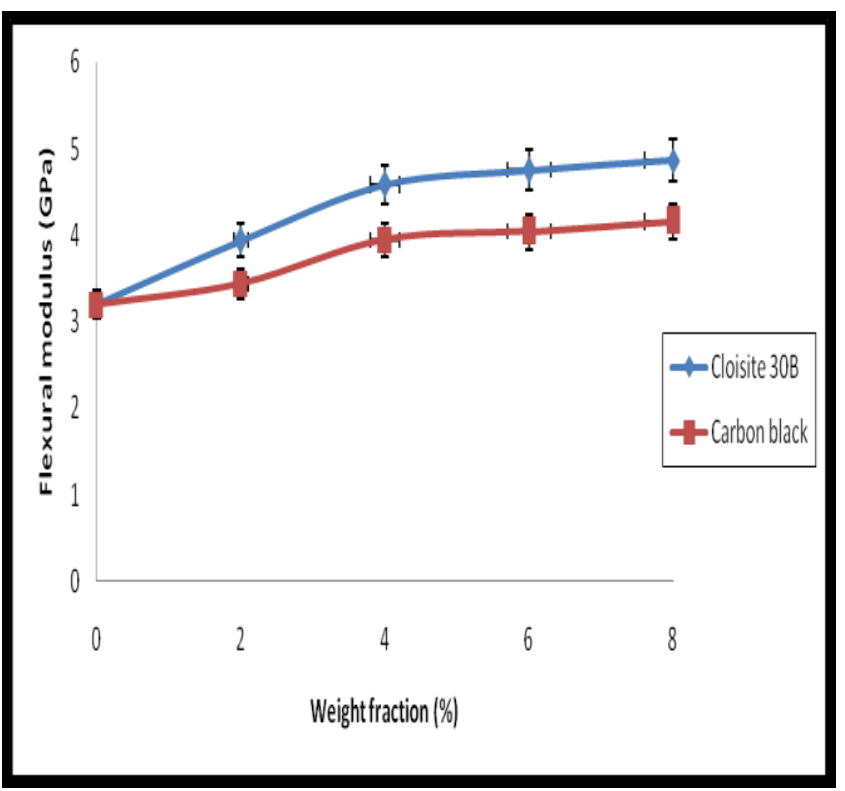

(b)

Figure 4: Flexural properties of $\mathrm{C} 30 \mathrm{~B} / \mathrm{UP}$ and $\mathrm{CB} / \mathrm{UP}$ (a) Flexural strength and (b) flexural modulus of nanocomposites 
Fig 4. (b) shows flexural modulus result for $\mathrm{C} 30 \mathrm{~B}$ and CB composites. Polyester C30B composites show higher modulus strength compare to $\mathrm{C} 30 \mathrm{~B}$ composites. Increasing of filler content had increased the flexural modulus of both composites. Shafi et al. [12] stated the presence of $\mathrm{C} 30 \mathrm{~B}$ in the UP strengthen and stiffness the inside matrix, positively increasing the bending of the nanocomposites. These due to the reinforcement of C30B is more compatible than that of $\mathrm{CB}$. The result also indicated that $\mathrm{CB}$ is less performance than $\mathrm{C} 30 \mathrm{~B}$ due to the increasing filler to some fraction will formed aggregated and low mechanical properties.

\subsection{Surface morphology}

Fig 5(a) and 4(b) shows SEM image from flexural fractured sample of both composites. Immiscible blend image was observed for CB composites, while homogenous blending image was observed for C30B composite. Dispersion of Cloisite 30B in the UP was well conducted, smooth surface and less aggregated with matrix as well. In this case, the external loaded in composite was separated uniformly in matrix and particles and continuously regains the strength by increase the modulus and also decrease the ductility of composite. CB/UP composite sample shows rough surface image and prove that incompatibility between matrix and filler affect the mechanical properties of $\mathrm{CB}$ polyester composite. This may be due to the high surface to ratio of $\mathrm{CB}$ when an excess amount of $\mathrm{CB}$ is added into composite which in turn leads to the poor dispersion or agglomeration of CB in matrix [9] Yuan bo et al. [5] stated that nanoclay was promising in the enhancement of long term durability in engineering applications by delaying the crack propagation.

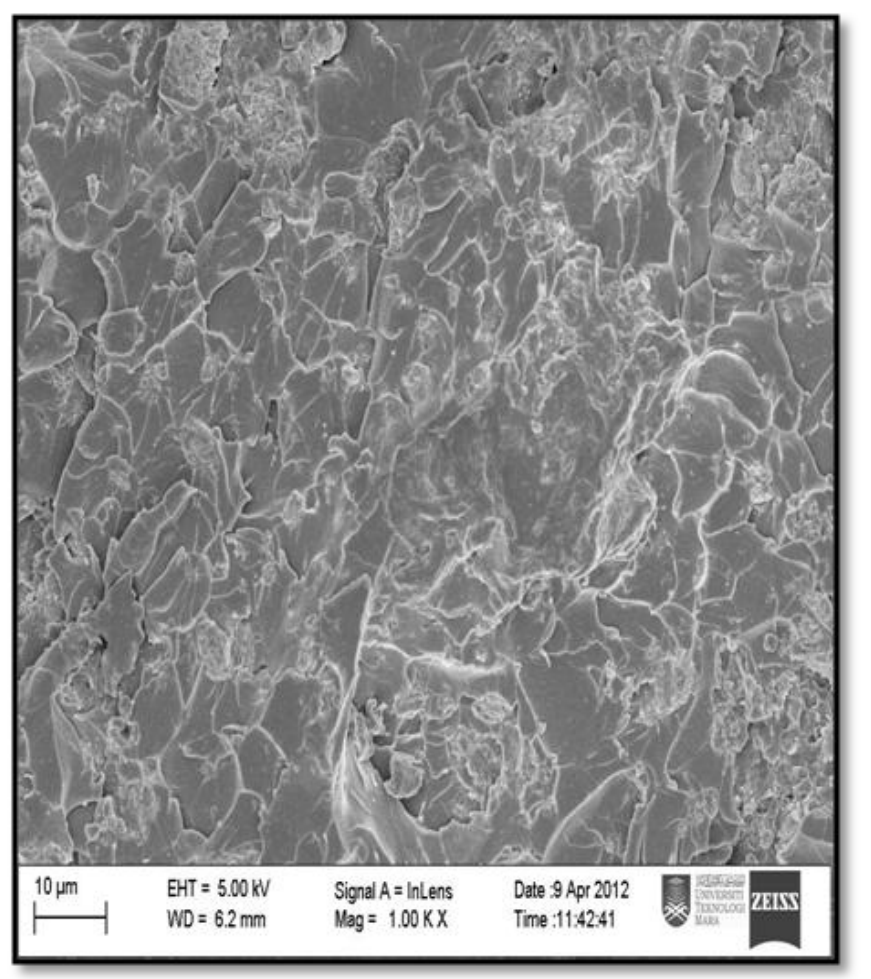

(a) $\mathrm{CB} / \mathrm{UP}$ composite

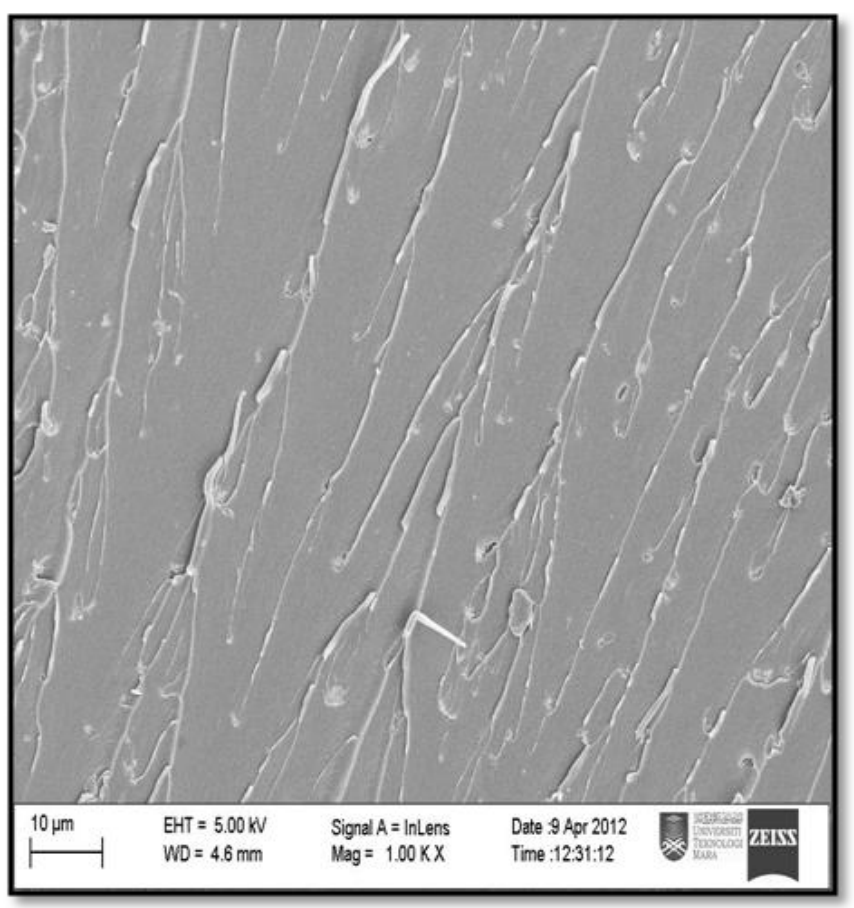

(b) $\mathrm{C} 30 \mathrm{~B} / \mathrm{UP}$ composite

Figure 5: FESEM images of composites magnified by 1000 (a) $\mathrm{CB} / \mathrm{UP}(\mathrm{b}) \mathrm{C} 30 \mathrm{~B} / \mathrm{UP}$

\section{Conclusion}

From this analysis, shows that addition of filler helps improving strength of polyester composites The mechanical properties of Cloisite $30 \mathrm{~B}(\mathrm{C} 30 \mathrm{~B})$ is good compare to carbon black ( $\mathrm{CB}$ polyester composite) generally. From the SEM observation, mechanicalmorphology relationship described that Cloisite 30B enhance the performance of composite. Cloisite 30B (C30B) is a good reinforcement material as compare to Carbon Black (CB) in polyester composite.

\section{Acknowledgement}

The authors would like to thanks Faculty of Applied Sciences, Universiti Teknologi Mara (UiTM), for the financial support.

\section{References}

1. E. G. William, A. B. Aldo, Polymer Nanocomposites: Synthetic and natural fillers a review. (2005)

2. J. Byung-Wan, P. Seung-Kook, K. Do-Keun, Mechanical properties of nano-MMT reinforced polymer composite and polymer concrete. Construction and Building Materials, 22, 14 (2008).

3. Y. Konishi, M. Cakmak, Nanoparticle induced network self-assembly in polymer-carbon black composites. Polymer, 47, 5371 (2006).

4. L. Yuanbo, L. Li, W. Qi, Z. Xin, Fracture properties of natural rubber filled with hybrid carbon black/nanoclay. J. Polymer Res, 18, 859 (2011). 
5. K. Vanja, G. Zoran, Crosslinking of an unsaturated polyester resin in the mould: Modelling and heat transfers studies. Applied Mathematical Modelling, 34, 1586 (2010).

6. D. J. Suh, Y. T. Lim, O. O. Park, The property and formation mechanism of unsaturated polyesterlayered silicate nanocomposite depending on the fabrication methods. Poly. 41, 8557-8563(2000).

7. N. N. Bonnia, S. H. Ahmad, I. Zainol, A. A. Mamun, M. D. H. Beg, A. K. Bledzki. Mechanical properties and environmental stress cracking resistance of rubber toughened polyester/kenaf composite. eXPRESS Polymer Letters, 4, 56 (2010).

8. I. Z. Ahmad, I. B. Zakaria, F. A. Ramli, A. Ahmad Marzuki, H. F. Abdul Aziz, Modification of epoxy resin using liquid natural rubber. Material Science Forum. 517, 272-274 (2006).

9. L. Xuefeng, L. Peiqing, G. Xin, W. Yupeng, Study on microstructure and mechanical properties of epoxy resin/carbon black composites prepared by in situ polymerization. Applied Mechanics and Materials, 109, 156 (2012).

10. Z. Quanlin, J. Zhijun, L. Xiaogong, Y. Zhengfeng, Effect of $\mathrm{Al}(\mathrm{OH}) 3$ particle fraction on mechanical properties of particle-reinforced composites using unsaturated polyester as matrix. J Fail. Anal. and Preven. 10, 518 (2010).

11. K. M. Pradip, K. G. Prasanta, K. B. Anik, Effect of nanoclays on physic-mechanical properties and adhesion of polyester-based polyurethane nanocomposites; structure-property correlations. J. Mater Sci, 44, 5867 (2009).

12. H. P. S. Abdul Khalil, P. Firoozian, I. O. Bakare, M. A Hazizan, M. N. Ahmad, Exploring biomass based carbon black as filler in epoxy composites: Flexural and thermal properties. Materials and Design, 31, 3421(2010). 